\title{
Antigenicity and conformational changes of $\beta$-lactoglobulin by dynamic high pressure microfluidization combining with glycation treatment
}

\author{
Junzhen Zhong, ${ }^{1}$ Yue Tu, ${ }^{1}$ Wei Liu, ${ }^{2}$ Yujia Xu, Chengmei Liu, and Ruyan Dun \\ State Key Laboratory of Food Science and Technology, Nanchang University, Nanchang 330047, China
}

\begin{abstract}
The combined effect of previous dynamic high-pressure microfluidization treatment $(40,80,120$, and 160 $\mathrm{MPa}$ ) and subsequent glycation with galacto-oligosaccharides (GOS) on the antigenicity of $\beta$-lactoglobulin ( $\beta$-LG) was investigated. The antigenicity of $\beta$-LG-GOS decreased at relatively low pressure $(\leq 120 \mathrm{MPa})$. Surface sulfhydryl group content of $\beta$-LG-GOS increased and surface hydrophobicity of $\beta$-LG-GOS decreased. Additionally, protein unfolding in $\beta$-LG-GOS samples was reflected by quenching of fluorescence intensity, the red-shift of fluorescence spectra, decreased UV absorption, and circular dichroism analysis, indicating tertiary and secondary structural changes of $\beta-\mathrm{LG}$. The conformational changes may contribute to the alteration of antigenicity.

Key words: $\beta$-lactoglobulin, antigenicity, dynamic high-pressure microfluidization combined with glycation, conformational change
\end{abstract}

\section{INTRODUCTION}

$\beta$-Lactoglobulin, the major whey protein, is a globular protein with a molecular mass of about $18.4 \mathrm{kDa}, 2$ disulfide bridges, and 1 residue of free Cys (Papiz et al., 1986). It is extensively used in food formulations due to its nutritive, biological, and functional properties (Akita and Nakai, 1990; Aguilera and Lillford, 2008). As a functional additive, $\beta-\mathrm{LG}$ is one of the major allergens that causes milk allergy (Exl and Fritsche, 2001). As antigenicity limits the application of $\beta$-LG in the food industry, numerous attempts have been made to reduce its antigenicity through physical treatments, such as heat treatment (Iametti et al., 2002) and high hydrostatic pressure treatment (López-Expósito et al., 2012); chemical treatments, such as glycation and phosphorylation (Enomoto et al., 2009; Li et al., 2011); and enzymatic treatments (Kim et al., 2007).

Received December 12, 2013.

Accepted March 15, 2014.

${ }^{1}$ These authors contributed equally to this work.

${ }^{2}$ Corresponding author: liuwei@ncu.edu.cn
In recent years, a great deal of attention has been focused on glycation to obtain modified proteins. Glycation with polysaccharides, such as dextran (Hattori, 2002) and carboxymethldextran (Hattori et al., 2000), and monosaccharides, such as galactose (Chevalier et al., 2001b) and glucose (Hiller and Lorenzen, 2010), have been reported, some of which were found to reduce antigenicity effectively. Our research group previously reported that glycation with fructo-oligosaccharides reduced antigenicity of $\beta$-LG (Zhong et al., 2013). We also reported that physical treatment with dynamic high-pressure microfluidization (DHPM) altered the antigenicity of $\beta$-LG (Zhong et al., 2012). However, little information is known about the effect of DHPM combined with subsequent glycation with galacto-oligosaccharides (GOS) on antigenicity and conformational changes of $\beta$-LG. The aim of the current study was to understand the effects of DHPM combined with glycation treatment on the antigenicity of $\beta-\mathrm{LG}$ by indirect competitive ELISA and conformational changes, such as free sulfhydryl content, surface hydrophobicity, UV absorption spectra, intrinsic emission fluorescence, and circular dichroism spectra of $\beta-\mathrm{LG}$.

\section{MATERIALS AND METHODS}

\section{Materials}

$\beta$-Lactoglobulin standard (L3908), GOS, and antirabbit IgG (A6154) were obtained from Sigma Chemical Company (St. Louis, MO). Galacto-oligosaccharides are nondigestible oligosaccharides comprising 2 to 20 molecules of galactose and 1 molecule of glucose. All other reagents were of analytical grade or better.

\section{DHPM Combined with Glycation Treatment}

According to our previous report (Zhong et al., 2011), DHPM treatment of $\beta$-LG was conducted under the following conditions. $\beta$-Lactoglobulin standard solutions $(1 \mathrm{mg} / \mathrm{mL})$ were treated to 3 passes at pressures of $0.1,40,80,120$, and $160 \mathrm{MPa}$ in a Microfluidizer processor (model M-110EH-30, Microfluidics, Newton, MA). Samples were collected and glycated with GOS immediately. 
According to the methods of Chevalier et al. (2001) and Zhong et al. (2013), with some modifications, glycation with GOS was conducted under the following conditions. The mass ratios of $\beta-\mathrm{LG}$ and GOS (1:4) were dissolved in $600 \mathrm{~mL}$ of distilled water and then lyophilized. The mixtures were incubated at $50^{\circ} \mathrm{C}$ at a relative humidity of $79 \%$ for $24 \mathrm{~h}$. After dialysis against distilled water and lyophilization, a crude $\beta$-LG-GOS conjugate was obtained. Free oligosaccharides were removed by salting out. The crude sample was dissolved in distilled water, and ammonium sulfate was added to a final concentration of $5 \mathrm{M}$. The precipitate was recovered by centrifugation $(48,400 \times g$ for $30 \mathrm{~min})$ at $20^{\circ} \mathrm{C}$. The purified conjugate was obtained by the molecular weight cut-off of dialysis tubing (14,000 Da) from Solarbio Chemical Company (Beijing, China) against distilled water and lyophilization. All glycation experiments were performed in triplicate.

$\beta$-Lactoglobulin heated at conjugate conditions without sugar (heated control) was named $\beta-L G$ (control), and unprocessed $\beta$-LG-GOS conjugate was named $\beta$-LG-GOS (0.1 MPa). Samples glycated with GOS after DHPM treatment at 40, 80, 120, $160 \mathrm{MPa}$ were named $\beta$-LG-GOS (40 MPa), $\beta$-LG-GOS (80 MPa), $\beta$-LG-GOS (120 MPa), and $\beta$-LG-GOS (160 MPa), respectively.

\section{SDS-PAGE Analysis}

The SDS-PAGE was carried out to confirm conjugate formation, using a $12 \%$ acryl amide separating gel and a $4 \%$ acryl amide stacking gel, as used by Balti et al. (2009) and Liu et al. (2010). Electrophoresis was run with a $5 \%$ (wt/vol) stacking gel and $15 \%$ (wt/vol) separating gel, with currents of 15 and $35 \mathrm{~mA}$, respectively. Samples were prepared by mixing $\beta-\mathrm{LG}$ at a $1: 1$ ( $\mathrm{vol} /$ vol) ratio with $\mathrm{pH} 6.8,0.5 \mathrm{M}$ Tris- $\mathrm{HCl}, 2 \mathrm{mg}$ of SDS, 2 $\mu \mathrm{L}$ of glycerol, $2 \mu \mathrm{L}$ of $\beta$-mercaptoethanol, and $0.04 \mathrm{mg}$ of bromophenol blue. Samples were heated at $100^{\circ} \mathrm{C}$ for 5 to 10 min before electrophoresis. After electrophoresis, the gels were stained with $0.25 \%$ Coomassie Brilliant Blue R-250 (Sangon Biotech Co., Ltd., Shanghai, China) for at least 30 min in 25\% methanol and $10 \%$ acetic acid and destained with 5\% methanol and 7.5\% acetic acid. The molecular weight markers used were 14, 20, 29, 44, 66, and $97 \mathrm{kDa}$.

\section{Antigenicity Analysis}

The antigenicity of different $\beta$-LG samples was estimated by an indirect competitive ELISA (Wroblewska et al., 2004; Zhong et al., 2011). Polyclonal IgY antibodies of rabbit, monospecific for $\beta-\mathrm{LG}$, were applied, detecting the antigenic response of $\beta$-LG (Kleber et al., 2004).
Microtiter plates with 96 wells (flat-bottomed; Costar, Corning, Corning, NY) were coated with $100 \mu \mathrm{L}$ /well of $1 \mu \mathrm{g} / \mathrm{mL}$ of antigen and were incubated overnight at $4^{\circ} \mathrm{C}$. Residual free binding sites were blocked with $1 \%$ pig gelatin in PBS/Tween solution (PBST) for 30 min at room temperature. The wells of the plates were washed 6 times with PBST. Competition was initiated by adding $50 \mu \mathrm{L}$ of either the standard or a sample solution containing 0.25 to $50 \mu \mathrm{g} / \mathrm{mL}$ of $\beta-\mathrm{LG}$ in PBST and $50 \mu \mathrm{L}$ of anti- $\beta$-LG-IgY $(10 \mu \mathrm{g} / \mathrm{mL})$ to the wells. The plates were incubated overnight at $4^{\circ} \mathrm{C}$. After removing the solutions, the wells were washed 6 times with PBST. A solution of $100 \mu \mathrm{L}$ of purified anti-rabbit IgG (A6154, Sigma Chemical Co.), diluted 1:10,000 in PBST, was added and the plates were incubated for 2 $\mathrm{h}$ at $37^{\circ} \mathrm{C}$. After washing, $50 \mu \mathrm{L}$ of $\mathrm{H}_{2} \mathrm{O}_{2}$-urea solution and $50 \mu \mathrm{L}$ of tetramethylenbenzidine solution were immediately added to each well. The reaction was stopped by adding $100 \mu \mathrm{L}$ of $1 M$ sulfuric acid. Absorption was measured at $450 \mathrm{~nm}$.

The antigenic response of the samples was calculated from a standard curve of $\beta$-LG, for which a linear logarithmic correlation was observed in the range of 0.01 to $400 \mu \mathrm{g} / \mathrm{mL}$ for $\beta$-LG. All analyses were carried out in triplicate and the averaged values were converted to concentration equivalents in micrograms per milliliter.

\section{Determination of Surface Sulfhydryl Group Content}

Surface sulfhydryl group (SH) contents of protein samples were determined using Ellman's reagent (Ellman, 1959; Sava et al., 2005; Zhong et al., 2012). Free SH contents for $\beta$-LG were obtained by adding $\beta-\mathrm{LG}$ samples $(1 \mathrm{mg} / \mathrm{mL})$ in $0.1 \mathrm{M}, \mathrm{pH} 8.0$ sodium phosphate buffer. The above solutions were incubated at $25^{\circ} \mathrm{C}$ for $1 \mathrm{~h}$, and then $50 \mu \mathrm{L}$ of each sample was extracted from the solutions after $1 \mathrm{~h}$ and $25 \mu \mathrm{L}$ of $0.01 \mathrm{M}$ 5,5'-dithiobis-2-nitrobenzoic acid was added to it. The solution was then diluted to $10 \mathrm{~mL}$ and UV absorbance at $412 \mathrm{~nm}$ was measured at $25^{\circ} \mathrm{C}$. The SH contents were calculated by the use of extinction coefficient of 2-nitro5-thiobenzoate at $412 \mathrm{~nm}, 13,600 M$ per centimeter, expressed as micromoles per gram of protein.

\section{Determination of Surface Hydrophobicity}

Surface hydrophobicity (Ho) was determined with the fluorescence probe 1-anilinonaphthalene-8-sulfonate (ANS ${ }^{-}$; Sigma Chemical Co.) according to the method of Haskard and Li-Chan (1998) and used by Shen and Tang (2012). Serial dilutions in $0.01 M$ phosphate buffer $(\mathrm{pH} 7.0)$ were prepared with the protein samples (stock solutions; $1.5 \% \mathrm{wt} / \mathrm{vol}$ ) to a final concentration of 0.004 to $0.02 \%$ (wt/vol). The $\mathrm{ANS}^{-}$solution $(8.0 \mathrm{mM}$ ) was 
also prepared in the same buffer. Twenty microliters of $\mathrm{ANS}^{-}$solution was added to $4 \mathrm{~mL}$ of each dilution and fluorescence intensity of the mixture was measured at 370 (excitation) and $470 \mathrm{~nm}$ (emission) using an F4500 fluorescence-spectrophotometer (Hitachi, Tokyo, Japan). The initial slope of the fluorescence intensity versus protein concentration $(\mathrm{mg} / \mathrm{mL}$ ) plot (calculated by linear regression analysis) was used as an index of Ho.

\section{Intrinsic Fluorescence and UV Absorption Spectra Analysis}

Fluorescence analyses were performed for samples. Fluorescence measurements were carried out in a Hitachi spectrofluorimeter (F-4500, Hitachi) using 10-mm² quartz cells and a protein concentration of $1 \mathrm{mg} / \mathrm{mL}$ in phosphate buffer $(10 \mathrm{~m} M, \mathrm{pH}$ 7.0). The excitation wavelength was $280 \mathrm{~nm}$; the emission spectrum was scanned from 300 to $450 \mathrm{~nm}$, using 5-nm bandwidth, with excitation and emission slits of 2.5 and $5.0 \mathrm{~nm}$, respectively, and at a scan speed of $240 \mathrm{~nm} / \mathrm{min}$ (de la Hoz and Netto, 2008; Zhong et al., 2012). The UV absorption spectra of samples were measured by a UVVIS 2510PC spectrophotometer (Shimadzu, Kyoto, Japan); UV absorption spectra were scanned from 200 to $360 \mathrm{~nm}$.

\section{Circular Dichroism Analysis}

Circular dichroism (CD) spectroscopy analyses were run for different samples according to Divsalar et al. (2009). The CD spectra of samples at $0.2 \mathrm{mg} / \mathrm{mL}$ for far-UV in $10 \mathrm{~m} M$ sodium phosphate buffer, $\mathrm{pH}$ 7.0, were collected using a MOS-450 spectropolarimeter (French Bio-Logic SAS Co., Claix, France), at $22^{\circ} \mathrm{C}$. A cylindrical quartz cuvette with a path length of 0.1 $\mathrm{cm}$ was used for collecting data in the far-UV (185-250 $\mathrm{nm})$ region. The scanning condition was $1-\mathrm{nm}$ step resolution for far-UV; both scans were performed using a $100-\mathrm{nm} / \mathrm{min}$ scan rate, $1.0 \mathrm{~nm}$ of bandwidth, and 4 scans, corrected by subtracting the buffer baseline spectrum. Structure predictions from CD spectra were obtained using the Contin LL program (de la Hoz and Netto, 2008; Zhong et al., 2012).

\section{Statistical Analysis}

The one-way ANOVA test for significant effects of treatments and assays was determined using SPSS 12.0.1 (SPSS Inc., Chicago, IL). Main effect differences were considered significant at $P \leq 0.05$. Mean separations were determined by Tukey's procedure for multiple comparisons. All experiments (CD analysis 4 times) were analyzed in triplicate.

\section{RESULTS AND DISCUSSION}

\section{Changes of Antigenicity of $\beta$-LG-GOS}

The antigenicity of $\beta$-LG-GOS samples were shown in Figure 1. It depicted the antigenicity values of samples obtained through glycation with GOS after DHPM treatment under 40, 80, 120, and $160 \mathrm{MPa}$. The antigenicity of $\beta$-LG (control) was $165.8 \mu \mathrm{g} / \mathrm{mL}$. It was showed that after glycation with GOS, the antigenicity of $\beta$-LG-GOS (0.1 MPa; $45.2 \mu \mathrm{g} / \mathrm{mL})$ decreased remarkably. The observed antigenicity decrease of protein after glycation was similar to that of $\beta$-LG modified by acidic oligosaccharides (Hattori et al., 2004), carboxymethyl dextran (Kobayashi, 2001), maltose (Li et al., 2011), and fructo-oligosaccharides (Zhong et al., 2013). Glycation with oligosaccharides was a significantly effective way to reduce antigenicity. The reason for reduced antigenicity of $\beta$-LG may be the conjugation of reducing carbohydrates to the $\varepsilon$-amino group of Lys during glycation and masking of some epitopes during glycation (Kobayashi, 2001; Hattori et al., 2004; Meltretter et al., 2007).

In our previous research, DHPM-modified $\beta$-LG standards showed a remarkable increase in antigenicity when treated to $80 \mathrm{MPa}$, However, in the current work, DHPM combined with glycation altered antigenicity according to pressure levels. At relatively low pressures $(\leq 120 \mathrm{MPa})$, antigenicity of $\beta$-LG-GOS was reduced and reached the greatest degree of reduction in $\beta$-LG-GOS at $80 \mathrm{MPa}(8.7 \mu \mathrm{g} / \mathrm{mL})$, which showed

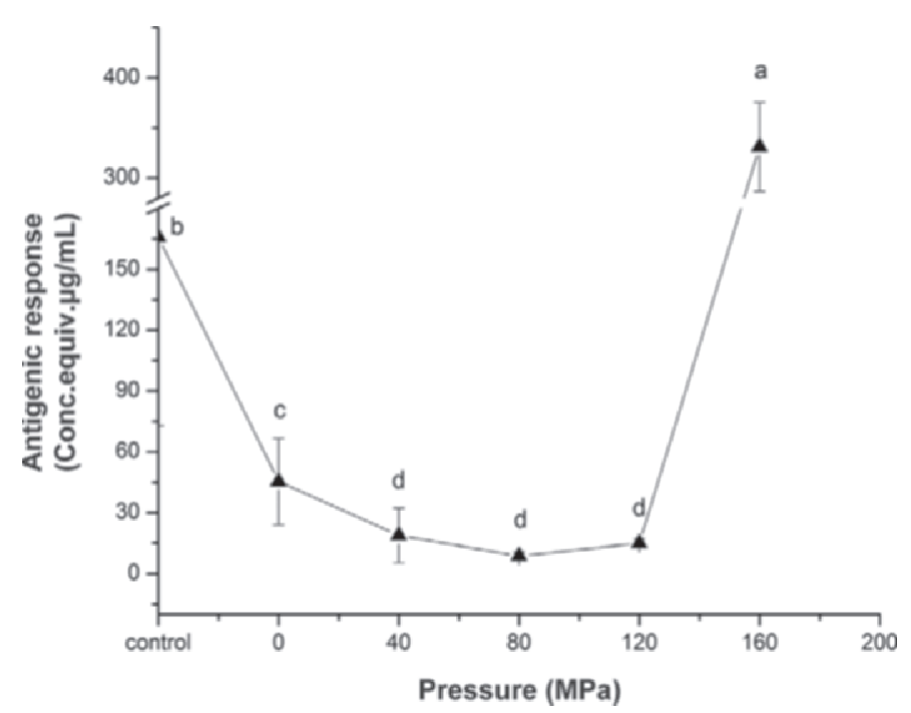

Figure 1. Antigenicity of $\beta$-LG (control), $\beta$-LG with galacto-oligosaccharides (GOS; $0.1 \mathrm{MPa}), \beta$-LG-GOS (40 MPa), $\beta$-LG-GOS (80 $\mathrm{MPa}), \beta-\mathrm{LG}-\mathrm{GOS}(120 \mathrm{MPa})$, and $\beta$-LG-GOS (160 MPa). Different letters $(\mathrm{a}-\mathrm{d})$ denote significant differences across different treatments $(P \leq 0.05)$. 
much lower antigenicity than those obtained by the 40 $(18.7 \mu \mathrm{g} / \mathrm{mL})$ and $120 \mathrm{MPa}(10.8 \mu \mathrm{g} / \mathrm{mL})$ treatment. But we were surprised to find that when the pressure grew to $160 \mathrm{MPa}$, the antigenicity increased to $331 \mu \mathrm{g} /$ $\mathrm{mL}$ and the value was about 2 times higher than that of $\beta$-LG (control). It could be seen that changes in the $\beta-L G$ antigenicity might largely depend on the glycation reaction conditions and processing treatments.

\section{Changes of Molecular Weight of $\beta-L G-G O S$}

The SDS-PAGE gel of samples with $\beta$-mercaptoethanol was shown in Figure 2. As it was seen, molecular weight of $\beta$-LG (control) was $18.4 \mathrm{kDa}$. After glycation with GOS, the bands of $\beta$-LG-GOS (0.1 MPa), $\beta$-LG-GOS $(40 \mathrm{MPa}), \quad \beta-L G-G O S(80 \mathrm{MPa}), \quad \beta-L G-G O S \quad(120$ $\mathrm{MPa}$ ), and $\beta$-LG-GOS (160 MPa) conjugates moved further (almost $20.1 \mathrm{kDa}$ ) in the gel compared with control sample. The band of treated samples with higher molecular weight indicated the formation of $\beta$-LGGOS conjugates compared with control $\beta$-LG. Broader and higher molecular weight bands were also observed by Qi et al. (2009) and Zhu et al. (2010) in proteins incubated with dextran. We previously reported that molecular weights of $\beta$-LG increased after glycation with fructo-oligosaccharides, too (Zhong et al., 2013). However, no noticeable differences in SDS-PAGE were observed among $\beta$-LG-GOS samples under different pressures. It was suggested that DHPM pretreatment mainly changed the conjugation reactions rather than the conjugation numbers between protein and sugar. Meanwhile, the different conjugation reactions may have resulted from different conformational changes of $\beta$-LG induced by DHPM pretreatment. In addition, according to Nakamura et al. (2005), antigenicity would be closely related to the conformational changes. To gain a better understanding, the conformational changes of 4 samples among $\beta$-LG (control), $\beta$-LG-GOS $(0.1 \mathrm{MPa}), \beta$-LG-GOS (80 MPa), and $\beta$-LG-GOS (160 $\mathrm{MPa}$ ) should be further examined.

\section{Changes of Surface SH Content and Ho of $\beta-L G-G O S$}

Surface SH content has been evaluated as an index of structural prediction of protein. In this work, the $\mathrm{SH}$ group content was found to be $52.44 \pm 1.97 \mu \mathrm{mol} / \mathrm{g}$ of protein in $\beta$-LG (control; Table 1). The surface SH content decreased to $50.25 \pm 1.93 \mu \mathrm{mol} / \mathrm{g}$ when glycated with GOS $(P \leq 0.05)$. The result was in accordance with Medrano et al. (2009), who found surface SH content decreased when $\beta$-LG was glycated with lactose. In our previous research (Zhong et al., 2012), after DHPM treatment of $\beta$-LG, the SH content was increased at $80 \mathrm{MPa}$ and decreased at $160 \mathrm{MPa}$ compared with na- tive $\beta$-LG. It was found that conformational changes of the $\beta$-LG molecule occurred in different degrees when treated at 80 and $160 \mathrm{MPa}$. But the situation was different when samples were treated by DHPM combining with glycation, which resulted in the increase of surface SH content. Surface SH content of $\beta$-LG-GOS (80 $\mathrm{MPa})$ and $\beta$-LG-GOS (160 MPa) increased to $55.67 \pm$ 0.41 and $58.18 \pm 1.71 \mu \mathrm{mol} / \mathrm{g}$, respectively, and values were higher than $\beta$-LG (control). The new increased SH group may be the result of cleavage of a disulfide bond into the surface. The increase in SH group content indicated conformational changes of protein according to Monahan et al. (1995).

Also, quantitative analysis of protein surface hydrophobicity is essential for accurate prediction of protein (Leonil et al., 1997). Surface hydrophobicity decreased during glycation. As shown in Table 1, compared with $\beta$-LG (control), the Ho of $\beta$-LG-GOS (0.1 MPa), $\beta$-LGGOS (80 MPa), and $\beta$-LG-GOS (160 MPa) declined from $1,048.5$ to $859.81,727.60$, and 880.08 , respectively. The result was in agreement with Galazka et al. (1999) and Corzo-Martínez et al. (2008), who also reported that glycated conjugates of $\beta$-LG decreased in hydrophobicity. According to van Teeffelen et al. (2005), the decline in Ho may be related with the fact that the conjugation of carbohydrates to the $\varepsilon$-amino group of Lys during glycation could bring more hydrophilic groups and lead to the blocking of Lys or Arg residues by GOS in the glycation conjugates (Sava et al., 2005; Gasymov and Glasgow, 2007). In this work, despite the minimum value of Ho found in $\beta$-LG-GOS (80 MPa), Ho change did not correlate with the varying of an-

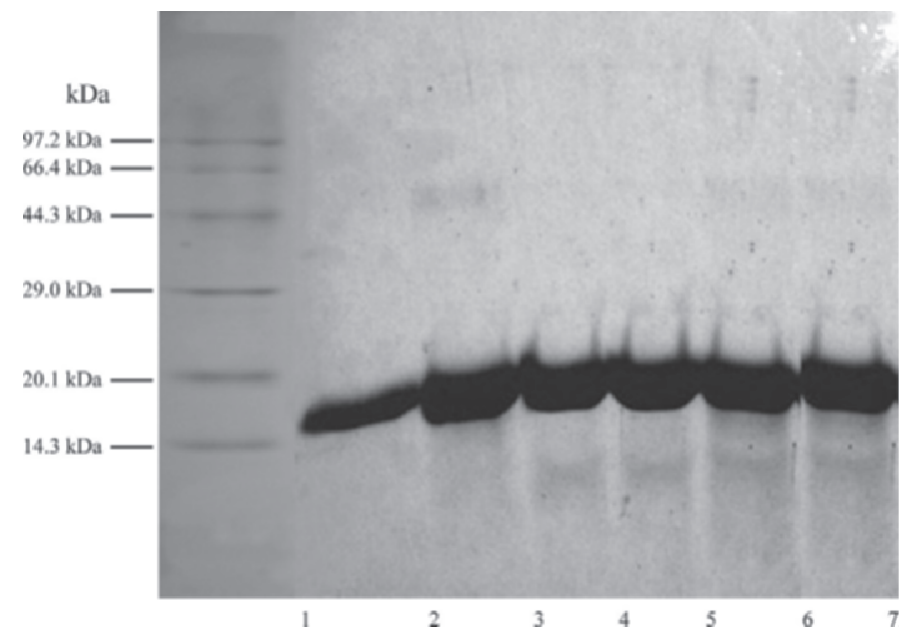

Figure 2. Sodium dodecyl sulfate-PAGE analysis. Lane $1=$ standard protein markers of different molecular weights; lanes 2, 3, 4, 5, 6, 7: $\beta$-LG (control), $\beta$-LG with galacto-oligosaccharides (GOS; 0.1 MPa), $\beta$-LG-GOS (40 MPa), $\beta$-LG-GOS (80 MPa), $\beta$-LG-GOS (120 $\mathrm{MPa})$, and $\beta$-LG-GOS (160 MPa). 
Table 1. Surface sulfhydryl group (SH) contents and surface hydrophobicity of $\beta$-LG (control) and $\beta$-LG with galacto-oligosaccharides (GOS)

\begin{tabular}{|c|c|c|c|c|}
\hline \multirow[b]{2}{*}{ Sample } & \multirow{2}{*}{$\begin{array}{c}\beta-\mathrm{LG} \\
(\text { control })\end{array}$} & \multicolumn{3}{|c|}{$\beta$-LG-GOS } \\
\hline & & $0.1 \mathrm{MPa}$ & $80 \mathrm{MPa}$ & $160 \mathrm{MPa}$ \\
\hline $\begin{array}{l}\text { Surface SH content }(\mu \mathrm{mol} / \mathrm{g}) \\
\text { Surface hydrophobicity }(\mathrm{Ho})\end{array}$ & $\begin{array}{l}52.44 \pm 1.97^{\mathrm{c}} \\
1,048.5\end{array}$ & $\begin{array}{l}50.25 \pm 1.93^{\mathrm{d}} \\
859.81\end{array}$ & $\begin{array}{l}55.67 \pm 0.41^{\mathrm{b}} \\
727.60\end{array}$ & $\begin{array}{l}58.78 \pm 1.71^{\mathrm{a}} \\
880.08\end{array}$ \\
\hline
\end{tabular}

${ }^{\mathrm{a}-\mathrm{d}}$ Different letters denote significant differences across different treatments $(P \leq 0.05)$.

tigenicity because it may be induced by the cleavage of hydrogen bonds and van der Waals forces and the exposure of hydrophilic amino acid residues in the inner site of proteins (Tanaka et al., 1996).

\section{Changes of Intrinsic Fluorescence and UV Absorption Spectroscopy of $\beta$-LG-GOS}

The intrinsic fluorescence of $\beta$-LG is mainly excited from Trp residues. As shown in Figure 3a, after glycation treatment, the fluorescence intensity of $\beta$-LG-GOS (0.1 MPa), $\beta$-LG-GOS (80 MPa), and $\beta$-LG-GOS (160 $\mathrm{MPa}$ ) decreased from 2,476 (control) to 1,684, 1,479, 1,746 , respectively, and fluorescence spectra showed a 4,6 , and $7 \mathrm{~nm}$ red shift of the maximum emission wavelength compared with $\beta-\mathrm{LG}$ (control), respectively. In our previous research (Zhong et al., 2012), DHPM treatment contributed to an increase in relative fluorescence intensity, but a red shift of the spectral peak was not observed. It may be noted that glycation contributes more significantly to protein intrinsic fluorescence. Concerning conformational characterization of glycoconjugates, a common decrease in intensity has been observed and red-shift can be seen after glycation (Sun et al., 2004; Wooster and Augustin, 2007; CorzoMartinez et al., 2008). Generally, the carbohydratebinding sites in the $\beta$-LG were mainly identified to be residue Lys (Hattori et al., 2004). The decrease of fluorescence intensity in the case of glycation conjugates was considered to have been due to a shielding effect by oligosaccharide chain bound to ${ }^{60} \mathrm{Lys}$ in this conjugate (Hattori et al., 2004). This red shift on the fluorescence emission spectrum was due to the fact that Trp residues moved from a less-polar environment to a more-polar region (Manderson et al., 1999). Glycation caused a reduction of intensity and a shift of Trp $\left({ }^{19} \operatorname{Trp}\right.$ and $\left.{ }^{61} \operatorname{Trp}\right)$ emission maximum in fluorescence spectra, which demonstrated protein unfolding (Wooster and Augustin, 2007; Liu et al., 2012).

The results of UV absorption spectra of $\beta$-LG (control), $\beta$-LG-GOS (0.1 MPa), $\beta$-LG-GOS (80 MPa), and $\beta$-LG-GOS (160 MPa) are shown in Figure 3b. The maximum absorption peak was at $280 \mathrm{~nm}$, which corresponded mainly to Tyr near $277 \mathrm{~nm}$ and an overlapping of Tyr and Trp near $283 \mathrm{~nm}$ (Kolakowski et al.,
2001). Glycation with GOS caused the reduction of UV absorption intensity. The absorption intensity of $\beta$-LG (control), $\beta$-LG-GOS (0.1 MPa), $\beta$-LG-GOS (80 $\mathrm{MPa})$, and $\beta$-LG-GOS (160 MPa) at $280 \mathrm{~nm}$ was 0.47 ,
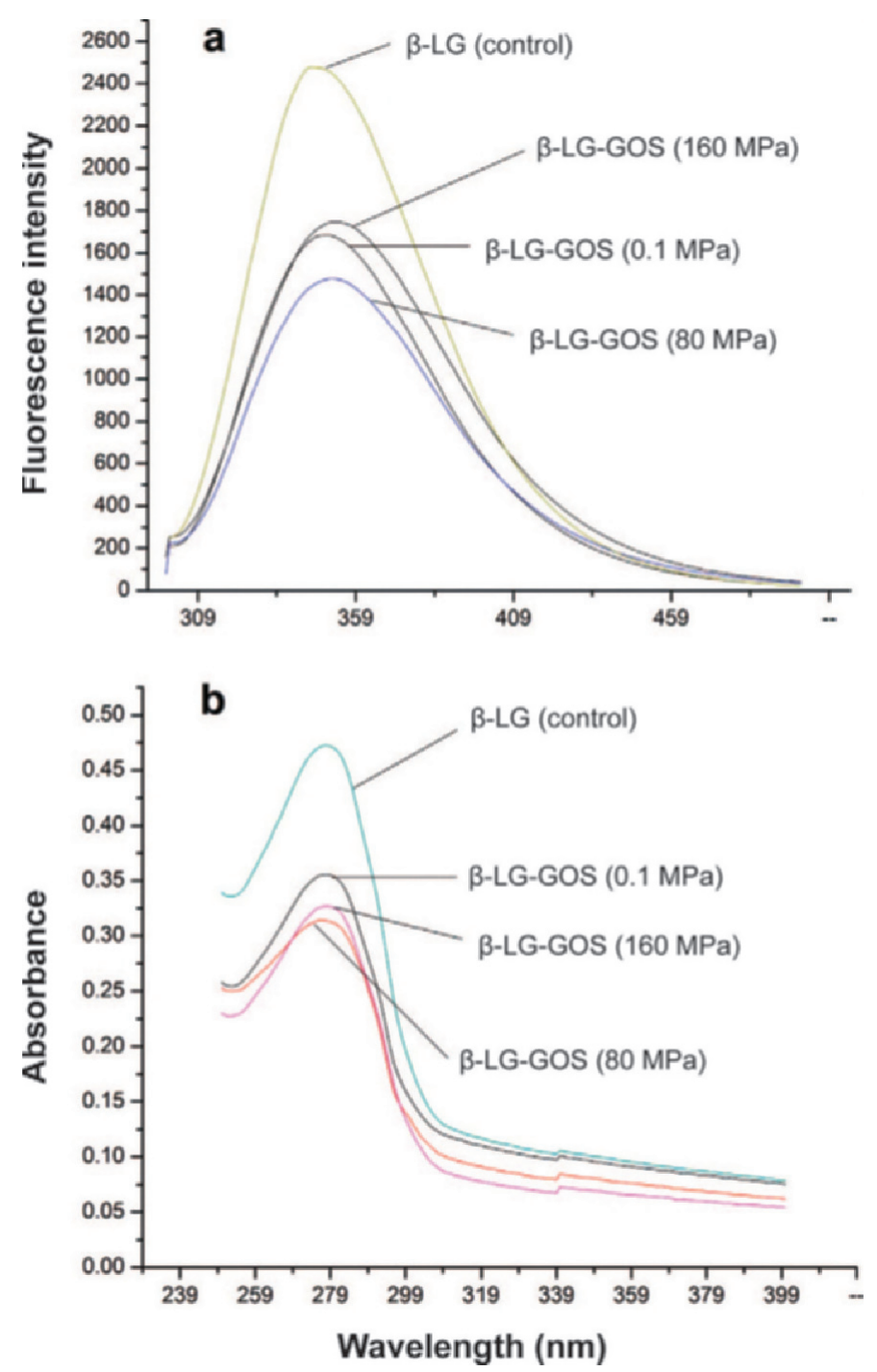

Figure 3. (a) Intrinsic fluorescent emission of $\beta-L G$ (control), $\beta$-LG with galacto-oligosaccharides (GOS; $0.1 \mathrm{MPa}), \beta$-LG-GOS (80 $\mathrm{MPa}$ ), and $\beta$-LG-GOS (160 MPa). (b) Ultraviolet absorption spectroscopy of $\beta$-LG (control), $\beta$-LG-GOS (0.1 MPa), $\beta$-LG-GOS (80 MPa), and $\beta$-LG-GOS (160 MPa), respectively. Color version available in the online PDF. 
Table 2. The calculated percentage content of secondary structures of $\beta$-LG (control) and $\beta$-LG with galactooligosaccharides (GOS)

\begin{tabular}{lcccr}
\hline & & \multicolumn{3}{c}{$\beta$-LG-GOS } \\
\cline { 3 - 5 } $\begin{array}{l}\text { Circular } \\
\text { dichroism (\%) }\end{array}$ & $\begin{array}{c}\beta \text {-LG } \\
\text { control) }\end{array}$ & $0.1 \mathrm{MPa}$ & $80 \mathrm{MPa}$ & $160 \mathrm{MPa}$ \\
\hline Helix & $19.9 \pm 0.14^{\mathrm{a}}$ & $20.3 \pm 0.63^{\mathrm{a}}$ & $10.1 \pm 0.07^{\mathrm{b}}$ & $1.6 \pm 0.15^{\mathrm{c}}$ \\
Sheet & $38.0 \pm 0.70^{\mathrm{b}}$ & $38.4 \pm 0.28^{\mathrm{b}}$ & $44.3 \pm 0.50^{\mathrm{a}}$ & $36.6 \pm 0.46^{\mathrm{c}}$ \\
Turn & $24.6 \pm 0.14^{\mathrm{b}}$ & $24.0 \pm 0.35^{\mathrm{b}}$ & $17.6 \pm 0.29^{\mathrm{c}}$ & $33.0 \pm 0.20^{\mathrm{a}}$ \\
Random & $17.5 \pm 0.42^{\mathrm{b}}$ & $17.3 \pm 0.56^{\mathrm{b}}$ & $28.0 \pm 0.21^{\mathrm{a}}$ & $28.8 \pm 0.26^{\mathrm{a}}$ \\
\hline
\end{tabular}

${ }^{\mathrm{a}-\mathrm{c}}$ Different letters denote significant differences across different treatments $(P \leq 0.05)$.

0.3534, 0.3116, and 0.3225, respectively. The lowest UV absorption intensity was also found in $\beta$-LG-GOS $(80$ $\mathrm{MPa}$ ), which was consistent with the analysis of fluorescence emission spectra. According to Housaindokht et al. (2001), the unfolding of protein decreased the UV absorption. Ultraviolet absorption spectra analysis indicated that the tertiary and quaternary structure of $\beta$-LG changed after DHPM combining with glycation treatment.

Antigenicity of $\beta$-LG depends on the epitopes, which are associated with the protein conformations and conformational flexibility (Kleber et al., 2004). When $\beta$-LG unfolded, GOS had more opportunities to bind with ${ }^{60}$ Lys residues, masking ${ }^{61} \operatorname{Trp}$ and epitopes. That would explain the low fluorescence intensity and the low antigenic response found in $\beta$-LG-GOS (80 MPa) samples and not in $\beta$-LG-GOS (0.1 MPa) or $\beta$-LG-GOS $(160 \mathrm{MPa})$. It may be responsible for conformational changes of the molecule, making the epitopes less accessible for the antibodies. The extent of protein unfolding in $\beta$-LG-GOS ( $80 \mathrm{MPa})$, caused by pre-DHPM treatment, may facilitate the glycation with GOS, resulting in masking of epitopes, and hence a great decrease of $\beta-L G$ antigenicity. Moreover, the change of fluorescence intensity of $\beta$-LG-GOS (0.1 MPa), $\beta$-LG-GOS (80 $\mathrm{MPa})$, and $\beta$-LG-GOS (160 MPa) was in accordance with their change of Ho value. The low fluorescence intensity and great degree of shift in $\beta$-LG-GOS (80 $\mathrm{MPa}$ ) samples indicated that the DHPM combined with glycation treatment was a significant factor affecting $\beta$-LG tertiary structure, and the results could be closely related to its low antigenicity.

\section{Changes of CD Analysis of $\beta-L G-G O S$}

$\beta$-Lactoglobulin is predominantly a $\beta$-sheet protein, consisting of 9 antiparallel $\beta$-strands and 1 major $\alpha$-helix at the $\mathrm{C}$ terminus of the molecule (Shibayama, 2008). As shown in Figure 4, the CD spectra showed a negative extreme around $213 \mathrm{~nm}$ and a positive maximum around $195 \mathrm{~nm}$, indicating a high content of $\beta$-strands, in accordance with the secondary structure content shown. The secondary structure composition of
$\beta$-LG (control) was approximately $19.9 \%$, $\alpha$-helix; $38 \%$, $\beta$-sheet; $24.6 \%, \beta$-turn; and $17.5 \%$, unordered coil (as calculated; Table 2). The calculated values are in the range of secondary structure content of native $\beta-\mathrm{LG}$ determined by other authors using CD (Qi et al., 1997; Croguennec et al., 2004).

As the secondary structure of protein depends on both the local sequence of amino acids and the interactions between different parts of molecule, the effects of glycation on secondary structure subjected to reaction conditions (glycation extent, reaction time, and the water content) and proteins. Some studies found that the secondary structure of protein was almost maintained after glycation (Hattori et al., 2004; Wong et al., 2011). According to other studies, however, glycation increased the $\alpha$-helix content and highly ordered structure content, mainly at the expense of $\beta$-sheet or random coil content (Liu et al., 2012). In the current work, the spectrum of the $\beta$-LG-GOS (0.1 MPa) showed a little increase

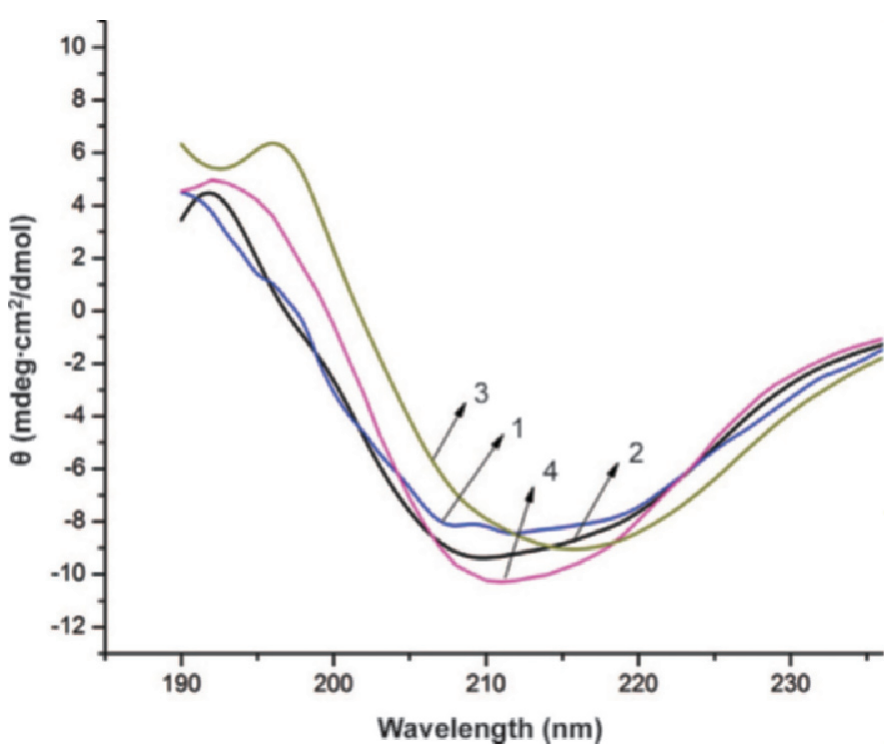

Figure 4. Far-UV circular dichroism spectra of secondary structures of samples; (1) $\beta$-LG (control), (2) $\beta$-LG with galacto-oligosaccharides (GOS; $0.1 \mathrm{MPa}$ ), (3) $\beta$-LG-GOS (80 MPa), and (4) $\beta$-LGGOS $(160 \mathrm{MPa}) . \theta=$ mean residual ellipticity. Color version available in the online PDF. 
in ellipticity and a shift of the positive and negative maximums to a higher wavelength compared with $\beta$-LG (control). Little change of $\alpha$-helix and $\beta$-sheet structure content was observed as calculated. With regard to $\beta$-LG-GOS (80 MPa), values of negative peaks at $213 \mathrm{~nm}$ decreased and shifted to a higher wavelength, accompanied by an increase in percentage content of $\beta$-strands, from 38.0 to $44.3 \%$, which generally referred to a continuous stretch of amino acids adopting an extended conformation. It has been found that the trough at $216 \mathrm{~nm}$ broadened and deepened, accompanied by the unfolding of $\beta$-LG (Considine et al., 2007).

The antigenicity of $\beta-\mathrm{LG}$ depends on the epitopes, which are closely related to protein secondary structures. According to previous literature, the best recognized epitopes of the $\beta$-LG were the fragments AA102-124, AA41-60, and AA149-162 (Sélo et al., 1999), of which AA102-124 and AA41-60 formed a protruding loop between $\beta$-strands $\mathrm{C}$ and $\mathrm{D}$ on the surface of the molecule (Wal, 2001). As the content of $\beta$-strands increased with the unfolding of the protein, some epitopes may be masked or disrupted after DHPM combined with glycation treatment, which contributed to a reduction of antigenicity in $\beta$-LG-GOS (80 MPa) samples. However, we also observed that random coil content increased at a more severe condition (160 MPa), along with a sharp reduction in percentage content of $\alpha$-helix, from 19.9 to $1.6 \%$, and a loss of $\beta$-sheet content, from 38.0 to $36.6 \%$. The sharp increase of antigenicity of $\beta$-LG-GOS (160 $\mathrm{MPa}$ ) samples may be explained by the detection of linear epitopes buried in the turn and random structures and some new epitopes formed by recombination of protein.

\section{CONCLUSIONS}

We investigated antigenicity and conformational changes of $\beta$-LG by DHPM combined with glycation treatment. We showed that antigenicity of $\beta-\mathrm{LG}$ was reduced at relatively low pressures $(\leq 120 \mathrm{MPa})$, and the lowest antigenicity was found in $\beta$-LG-GOS (80 $\mathrm{MPa}$ ) samples. The DHPM combined with glycation treatment resulted in an increase of the surface $\mathrm{SH}$ content and a decrease of Ho. Moreover, quenching of fluorescence intensity, the red-shift of fluorescence spectra, decreased UV absorption, and CD analysis indicated protein unfolding and changes in the secondary structure. All of these conformational changes may contribute to antigenicity changes of $\beta-\mathrm{LG}$, whereas more profound reasons should be explored further.

\section{ACKNOWLEDGMENTS}

This study was supported financially by the National Natural Science Foundation of China (Beijing, China;
21366021), the Research Program of State Key Laboratory of Food Science and Technology, Nanchang University (SKLF-MB-201004), and the Research Fund for the Doctoral Program of Higher Education of China (Beijing, China; 20103601110002).

\section{REFERENCES}

Aguilera, J. M., and P. J. Lillford. 2008. Food Materials Science: Principles and Practice. Springer Science \& Business Media LLC, New York, NY.

Akita, E. M., and S. Nakai. 1990. Lipophilization of B-lactoglobulin: Effect on hydrophobicity, conformation and surface functional properties. J. Food Sci. 55:711-717.

Balti, R., A. Barkia, A. Bougatef, N. Ktari, and M. Nasri. 2009. A heat-stable trypsin from the hepatopancreas of the cuttlefish ( $S e$ pia officinalis): Purification and characterisation. Food Chem. 113:146-154.

Chevalier, F., J. M. Chobert, Y. Popineau, M. G. Nicolas, and T. Haertle. 2001. Improvement of functional properties of $\beta$-lactoglobulin glycated through the Maillard reaction is related to the nature of the sugar. Int. Dairy J. 11:145-152.

Considine, T., H. A. Patel, H. Singh, and L. K. Creamer. 2007. Influence of binding conjugated linoleic acid and myristic acid on the heat- and high-pressure-induced unfolding and aggregation of B-lactoglobulin B. Food Chem. 102:1270-1280.

Corzo-Martínez, M., F. J. Moreno, A. Olano, and M. Villamiel. 2008. Structural characterization of bovine $\beta$-lactoglobulin galactose/ tagatose Maillard complexes by electrophoretic, chromatographic and spectroscopic methods. J. Agric. Food Chem. 56:4244-4252.

Croguennec, T., D. Molle, R. Mehra, and S. Bouhallab. 2004. Spectroscopic characterization of heat-induced nonnative $\beta$-lactoglobulin monomers. Protein Sci. 13:1340-1346.

de la Hoz, L., and F. M. Netto. 2008. Structural modifications of beta-lactoglobulin subjected to gamma radiation. Int. Dairy J. 18:1126-1132.

Divsalar, A., A. A. Saboury, F. Ahmad, and A. A. Moosavi-Movahedi. 2009. Effects of temperature and chromium (III) ion on the structure of bovine $\beta$-lactoglobulin A. J. Braz. Chem. Soc. 20:17821789 .

Ellman, G. L. 1959. Tissue sulfhydryl groups. Arch. Biochem. Biophys. 82:70-77.

Enomoto, H., Y. Hayashi, C. P. Li, S. Ohki, H. Ohtomo, M. Shiokawa, and T. Aoki. 2009. Glycation and phosphorylation of alpha-lactalbumin by dry-heating: Effect on protein structure and physiological functions. J. Dairy Sci. 92:3057-3068.

Exl, B. M., and R. Fritsche. 2001. Cow's milk protein allergy and possible means for its prevention. Nutrition 17:642-651.

Galazka, V. B., D. Smith, E. Dickinson, and D. A. Ledward. 1999. Effect of high pressure on protein-polysaccharide complexes. Food emulsions and foams: Interfaces, interactions and stability. Pages 104-116 in Proc. Int. Conf. Food Emulsions and Foams: Interfaces, Interactions and Stability, Seville, Spain. Royal Society of Chemistry, Cambridge, UK.

Gasymov, O. K., and B. J. Glasgow. 2007. ANS fluorescence: Potential to augment the identification of the external binding sites of proteins. Biochim. Biophys. Acta 1774:403-411.

Haskard, C. A., and E. C. Y. Li-Chan. 1998. Hydrophobicity of bovine serum albumin and ovalbumin determined using uncharged (PRODAN) and anionic $\left(\mathrm{ANS}^{-}\right)$fluorescent probes. J. Agric. Food Chem. 46:2671-2677.

Hattori, M. 2002. Functional improvements in food proteins in multiple aspects by conjugation with saccharides: Case studies of $\beta$-lactoglobulin-acidic polysaccharides conjugates. Food Sci. Res. 8:291-299.

Hattori, M., N. Koichi, and A. Akio. 2000. Functional changes in $\beta$-lactoglobulin by conjugation with cationic saccharides. J. Agric. Food Chem. 48:2050-2056. 
Hattori, M., S. Miyakawa, and Y. Ohama. 2004. Reduced immunogenicity of $\beta$-lactoglobulin by conjugation with acidic oligosaccharides. J. Agric. Food Chem. 52:4546-4553.

Hiller, B., and P. C. Lorenzen. 2010. Functional properties of milk proteins as affected by Maillard reaction induced oligomerisation. Food Res. Int. 43:1155-1166.

Housaindokht, M. R., J. Chamani, A. A. Saboury, A. A. MoosaviMovahedi, and M. Bahrololoom. 2001. Three binding sets analysis of $\alpha$-lactalbumin by interaction of tetradecyl trimethyl ammonium bromide. Bull. Korean Chem. Soc. 22:145-148.

Iametti, S., P. Rasmussen, H. Frokiaer, P. Ferranti, F. Addeo, and F. Bonomi. 2002. Proteolysis of bovine $\beta$-lactoglobulin during thermal treatment on subdenaturing conditions highlights some structural features of the temperature-modified protein and yields fragments with low immunoreactivity. Eur. J. Biochem. 269:1362-1372.

Kim, S. B., K. S. Ki, and M. A. Khan. 2007. Peptic and tryptic hydrolysis of native and heated whey protein to reduce its antigenicity. J. Dairy Sci. 90:4043-4050.

Kleber, N., I. Krause, S. Illgner, and J. Hinrichs. 2004. The antigenic response of beta-lactoglobulin is modulated by thermally induced aggregation. Eur. Food Res. Technol. 219:105-110.

Kobayashi, K. 2001. Reduced immunogenicity of $\beta$-lactoglobulin by conjugation with carboxymethyl dextran differing in molecular weight. J. Agric. Food Chem. 49:823-831.

Kolakowski, P., E. Dumay, and J. C. Cheftel. 2001. Effects of high pressure and low temperature on $\beta$-lactoglobulin unfolding and aggregation. Food Hydrocoll. 15:215-232.

Leonil, J., D. Molle, J. Fauquant, L. Maubois, R. J. Pearce, and S. Bouhallab. 1997. Characterization by ionization mass spectrometry of lactosyl $\beta$-lactoglobulin conjugates formed during heat treatment of milk and whey and identification of one lactose-binding site. J. Dairy Sci. 80:2270-2281.

Li, Z., Y. Luo, and L. Feng. 2011. Effects of Maillard reaction conditions on the antigenicity of $\alpha$-lactalbumin and $\beta$-lactoglobulin in whey protein conjugated with maltose. Eur. Food Res. Technol. 233:387-394

Liu, J. H., Q. Ru, and Y. Ding. 2012. Glycation a promising method for food protein modification: Physicochemical properties and structure, a review. Food Res. Int. 49:170-183.

Liu, W., Z. Q. Zhang, C. M. Liu, M. Y. Xie, Z. C. Tu, J. H. Liu, and R. H. Liang. 2010. The effect of dynamic high-pressure microfluidization on the activity, stability and conformation of trypsin. Food Chem. 123:616-621.

López-Expósito, I., R. Chicón, and J. Belloque. 2012. In vivo methods for testing allergenicity show that high hydrostatic pressure hydrolysates of $\beta$-lactoglobulin are immunologically inert. J. Dairy Sci. 95:541-548.

Manderson, G. A., M. J. Hardman, and L. K. Creamer. 1999. Effect of heat treatment on bovine $\beta$-lactoglobulin A, B and C explored using thiol availability and fluorescence. J. Agric. Food Chem. 47:3617-3627

Medrano, A., C. Abirached, L. Panizzolo, P. Moyna, and M. C. Anon. 2009. The effect of glycation on foam and structural properties of B-lactoglobulin. Food Chem. 113:127-133.

Meltretter, J., S. Seeber, and A. Humeny. 2007. Site-specific formation of Maillard, oxidation, and condensation products from whey proteins during reaction with lactose. J. Agric. Food Chem. $55: 6096-6103$.

Monahan, F. J., J. B. German, and J. E. Kinsella. 1995. Effect of $\mathrm{pH}$ and temperature on protein unfolding and thiol-disulfide interchange reactions during heat-induced gelation of whey proteins. J. Agric. Food Chem. 43:46-52.

Nakamura, A., K. Watanabe, and T. Ojima. 2005. Effect of Maillard reaction on allergenicity of scallop tropomyosin. J. Agric. Food Chem. 53:7559-7564.

Papiz, M. Z., L. Sawyer, E. E. Eliopoulos, A. C. T. North, J. B. C Findlay, R. Sivaprasadrao, T. A. Jones, M. E. Newcomer, and P.
J. Kraulis. 1986. The structure of $\beta$-lactglobulin and its similarity to plasma retinol binding protein. Nature 324:383-385.

Qi, J. R., X. Q. Yang, and J. S. Liao. 2009. Improvement of functional properties of acid-precipitated soy protein by the attachment of dextran through Maillard reaction. Int. J. Food Sci. Technol. 44:2296-2302.

Qi, X. L., C. Holt, D. McNulty, D. T. Clarke, S. Brownlow, and G. R. Jones. 1997. Effect of temperature on the secondary structure of $\beta$-lactoglobulin at $\mathrm{pH} 6.7$, as determined by $\mathrm{CD}$ and IR spectroscopy: A test of the molten globule hypothesis. Biochem. J. 324:341-346.

Sava, N., I. Van der Plancken, W. Claeys, and M. Hendrickx. 2005. The kinetics of heat-induced structural changes of beta-lactoglobulin. J. Dairy Sci. 88:1646-1653.

Sélo, I., G. Clement, and H. Bernard. 1999. Allergy to bovine $\beta$-lactoglobulin: Specificity of human IgE to tryptic peptides. Clin. Exp. Allergy 29:1055-1063.

Shen, L., and C.-H. Tang. 2012. Microfluidization as a potential technique to modify surface properties of soy protein isolate. Food Res. Int. 48:108-118.

Shibayama, N. 2008. Circular dichroism study on the early folding events of beta-lactoglobulin entrapped in wet silica gels. FEBS Lett. 582:2668-2672.

Sun, Y., S. Hayakawa, and K. Izumori. 2004. Modification of ovalbumin with a rare ketohexose through the Maillard reaction: Effect on protein structure and gel properties. J. Agric. Food Chem. $52: 1293-1299$

Tanaka, N., Y. Tsurui, and I. Kobayashi. 1996. Modification of the single unpaired sulfhydryl group of $\beta$-1actoglobulin under high pressure and the role of intermolecular S-S exchange in the pressure denaturation. Int. J. Biol. Macromol. 19:63-68.

van Teeffelen, A. M. M., K. Broersen, and H. H. J. de Jongh. 2005. Glycosylation of $\beta$-lactoglobulin lowers the heat capacity change of unfolding; a unique way to affect protein thermodynamics. Protein Sci. 14:2187-2194.

Wal, J. M. 2001. Structure and function of milk allergens. Allergy 56:35-38.

Wong, B. T., L. Day, and M. A. Augustin. 2011. Deamidated wheat protein-dextran Maillard conjugates: Effect of size and location of polysaccharide conjugated on steric stabilization of emulsions at acidic pH. Food Hydrocoll. 25:1424-1432.

Wooster, T. J., and M. A. Augustin. 2007. Rheology of whey proteindextran conjugate films at the air/water interface. Food Hydrocoll. 21:1072-1080.

Wroblewska, B., M. Karamac, R. Amarowicz, A. Szymkiewicz, A. Troszynska, and E. Kubicka. 2004. Immunoreactive properties of peptide fractions of cow whey milk proteins after enzymatic hydrolysis. Int. J. Food Sci. Technol. 39:839-850.

Zhong, J. Z., C. M. Liu, and W. Liu. 2011. Effect of dynamic highpressure microfluidization at different temperatures on the antigenic response of bovine $\beta$-lactoglobulin. Eur. Food Res. Technol 233:95-102.

Zhong, J. Z., W. Liu, and C. M. Liu. 2012. Aggregation and conformational changes of bovine $\beta$-lactoglobulin subjected to dynamic high-pressure microfluidization in relation to antigenicity. J. Dairy Sci. 95:4237-4245.

Zhong, J. Z., Y. J. Xu, and W. Liu. 2013. Antigenicity and functional properties of $\beta$-lactoglobulin conjugated with fructo-oligosaccharides in relation to conformational changes. J. Dairy Sci. 96:2808-2815.

Zhu, D., S. Damodaran, and J. A. Lucey. 2010. Physicochemical and emulsifying properties of whey protein isolate (WPI)-dextran conjugates produced in aqueous solution. J. Agric. Food Chem. 58:2988-2994. 